\title{
Synthesis of Nitrogen-Doped Carbon Nanotubes Using Injection-Vertical Chemical Vapor Deposition: Effects of Synthesis Parameters on the Nitrogen Content
}

\author{
Abdouelilah Hachimi, ${ }^{1}$ Belabbes Merzougui, ${ }^{2,3}$ Abbas Hakeem, ${ }^{1}$ Tahar Laoui, ${ }^{4}$ \\ Greg M. Swain, ${ }^{5}$ Qiaowan Chang, ${ }^{6}$ Minhua Shao, ${ }^{6}$ and Muataz Ali Atieh ${ }^{2,3}$ \\ ${ }^{1}$ Center of Excellence in Nanotechnology, King Fahd University of Petroleum and Minerals, Dhahran 31261, Saudi Arabia \\ ${ }^{2}$ Qatar Environment \& Energy Research Institute (QEERI), Qatar Foundation, Doha, Qatar \\ ${ }^{3}$ College of Science and Engineering, Hamad Bin Khalifa University (HBKU), Qatar Foundation, Doha, Qatar \\ ${ }^{4}$ Department of Mechanical Engineering, King Fahd University of Petroleum and Minerals, Dhahran 31261, Saudi Arabia \\ ${ }^{5}$ Department of Chemistry, Michigan State University, East Lansing, MI 48824, USA \\ ${ }^{6}$ Department of Chemical and Biomolecular Engineering, Hong Kong University of Science and Technology, \\ Clear Water Bay, Hong Kong
}

Correspondence should be addressed to Belabbes Merzougui; bmerzougui@qf.org.qa,

Tahar Laoui; tlaoui@kfupm.edu.sa, and Muataz Ali Atieh; mhussien@qf.org.qa

Received 1 September 2015; Accepted 3 November 2015

Academic Editor: Hassan Karimi-Maleh

Copyright (C) 2015 Abdouelilah Hachimi et al. This is an open access article distributed under the Creative Commons Attribution License, which permits unrestricted use, distribution, and reproduction in any medium, provided the original work is properly cited.

\begin{abstract}
Nitrogen-doped CNTs (N-CNTs) were synthesized using an injection-vertical chemical vapor deposition (IV-CVD) reactor. This type of reactor is quite useful for the continuous mass production of CNTs. In this work, the optimum deposition conditions for maximizing the incorporation of nitrogen were identified. Ferrocene served as the source of the Fe catalyst and was dissolved in acetonitrile, which served as both the hydrocarbon and nitrogen sources. Different concentrations of ferrocene in acetonitrile were introduced into the top of a vertically aligned reactor at a constant flow rate with hydrogen serving as the carrier. The effects of hydrogen flow rate, growth temperature, and catalyst loading (Fe from the ferrocene) on the microstructure, elemental composition, and yield of N-CNTs were investigated. The N-CNTs possessed a bamboo-like microstructure with a nitrogen doping level as high as 14 at. $\%$ when using 2.5 to $5 \mathrm{mg} / \mathrm{mL}$ of the ferrocene/acetonitrile mixture at $800^{\circ} \mathrm{C}$ under a $1000 \mathrm{sccm}$ flow of hydrogen. A production rate of $100 \mathrm{mg} / \mathrm{h}$ was achieved under the optimized synthesis conditions.
\end{abstract}

\section{Introduction}

CNTs and nitrogen-doped CNTs as emerging materials for many applications can be synthesized by many methods, such as arc-discharge, laser ablation, spray pyrolysis, and chemical vapor deposition (CVD). CVD method can be categorized into thermal-assisted [1-3] and plasma-assisted [4] processes. Due to the strong electric fields in plasma sheaths, the growth of carbon materials by plasma CVD tends to have an individually and vertically free-standing shape $[4,5]$. For many years, horizontally aligned CVD reactors have been used to produce carbon materials in variety of forms including aligned or entangled, straight or coiled, and even a desired architecture of nanotubes at predefined sites on a patterned substrate with high purity but with low yield (few grams) [6, 7]. Vertically aligned CVD reactors with different synthesis mechanisms have been used to produce large quantities in the order of $\mathrm{kg} / \mathrm{h}$ [8-13]. Recently, great attentions have been devoted to the study of nitrogen-doped carbon nanotubes (N-CNTs) because of their excellent properties, especially the electrical conductivity and electrocatalytic activity for oxygen reduction reaction $[1,2,14-22]$.

Boncel et al. [23] pointed out that the synthesis of $\mathrm{N}$ CNTs using an injection CVD technique has been typically 
carried out using a horizontal reactor. Many factors including reaction temperatures, types of carrier gas and reactors, flow rates, carbon and nitrogen sources, and catalysts affect the shape, nitrogen content, and properties of N-CNTs. The reaction temperature plays a key role in determining the binding configuration of nitrogen atoms to the surrounding carbon atoms. For instance, Lee et al. [2] and Koós et al. [24] found that nitrogen insertion into the CNT microstructure depended inversely on the growth temperature. Yadav et al. [25], however, revealed that N-doped CNTs grown at low temperatures acquired a higher degree of microstructural disorder associated with the higher nitrogen doping. The effect of the carrier gas, commonly hydrogen, has been widely studied. The hydrogen was found to decrease the amount of nitrogen incorporated onto the $\mathrm{N}$-CNTs owing to the equilibrium in the reactor between nitrogen and hydrogen radicals leading to the formation of stable gases such as $\mathrm{HCN}$ and $\mathrm{NH}_{3}[26,27]$. In other words, the added hydrogen can lead to gas phase reactions that decrease the levels of reactive nitrogen species, such as $\mathrm{CN}^{*}$. N-CNTs have been produced using different sources of carbon and nitrogen such as pyridine [28], melamine [29], and acetonitrile [30, 31] and catalyst sources such as ferrocene $[32,33]$ and nickelocene $[34,35]$.

The incorporation of nitrogen changes the overall microstructure of CNTs and subsequently alters their physical, chemical, and electrical properties. In other words, the physiochemical properties of nitrogen-doped CNTs strongly depend on the nitrogen doping level, crystallinity, and nanotube dimensions such as diameter and wall thickness [14]. Several bonding configurations that result from nitrogen insertion into the lattice structure have been reported, namely, $\mathrm{N}$-pyridinic, $\mathrm{N}$-pyrrolic, $\mathrm{N}$-quaternary, and $\mathrm{N}$-oxides $[14,36,37]$.

In the present study, an injection-vertical CVD (IV-CVD) reactor was constructed and used to synthesize N-CNTs. To the best of our knowledge, this is the first study using an IVCVD reactor to produce $\mathrm{N}-\mathrm{CNT}$. Our motivation of using such a reactor design is its capability of mass production of $\mathrm{N}$-CNTs in a continuous process, which is highly desirable for industrial applications. The overall goal of this work is to identify the optimum deposition parameters for producing nitrogen-doped CNTs with the highest nitrogen content. The effects of the synthesis parameters, specifically the hydrogen flow rate, growth temperature, and catalyst loading, were investigated to determine their correlations with the levels of nitrogen doping.

\section{Experiments}

2.1. Synthesis of N-CNTs. An injection-vertical chemical vapor deposition (IV-CVD) system was used for growing the N-CNTs. Figure 1 shows a schematic diagram of the reactor that consists of a vertically aligned quartz tube $(10 \mathrm{~cm}$ diameter, $100 \mathrm{~cm}$ height) heated by a tube furnace. The reactive gases were introduced at the top of the reactor.

For synthesis of the N-CNTs, Ar gas was used for flushing the reactor. The deposition temperature (700 to $\left.1000^{\circ} \mathrm{C}\right)$, hydrogen $\left(\mathrm{H}_{2}\right)$ flow rate $(750$ to $2000 \mathrm{~mL} / \mathrm{min})$, and ferrocene $(\mathrm{FcH}) /$ acetonitrile $(\mathrm{ACN})$ concentration (2.5$20 \mathrm{mg} / \mathrm{mL}$ ) were systematically varied to obtain the highest nitrogen doping. The FcH/ACN solution was passed into the top of the vertical reactor for $1 \mathrm{~h}$ at a constant flow rate of $30 \mathrm{~mL} / \mathrm{h}$. The deposition time was typically $1 \mathrm{~h}$. After growth, the reactor was allowed to cool to room temperature under an Ar gas flow. The N-CNTs were recovered from the inner wall as well as from the collector at the bottom of the reactor and subsequently weighted and characterized. In order to better understand the role of incorporated nitrogen in the morphology and microstructure, nitrogen-free CNT samples were also synthesized in the same IV-CVD reactor using $\mathrm{FcH} /$ para-xylene at $5 \mathrm{mg} / \mathrm{mL}$ under an $\mathrm{H}_{2}$ flow rate of $1000 \mathrm{~mL} / \mathrm{min}$ and a deposition temperature of $800^{\circ} \mathrm{C}$.

2.2. Characterizations of N-CNTs. A field emission scanning electron microscope (FE-SEM), equipped with energydispersive X-ray spectroscopy (EDS) (Tescan Lyra-3), was used to analyze the morphology and elemental composition of N-CNTs. To quantify the nitrogen content, boron nitride (BN) and graphite were used for calibration of the EDS measurements. X-ray diffraction patterns were collected with a Rigaku Miniflex II instrument using a CuK $\alpha 1$ (1.5406 ̊) source line at $30 \mathrm{kV}$ and $15 \mathrm{~mA}$. The XRD patterns were recorded in the static scanning mode from $2 \theta=5$ to $60^{\circ}$ at a detector angular speed of $0.5^{\circ} / \mathrm{min}$ and a step size of $0.02^{\circ}$. Matching crystal lattice parameters and space group analysis were determined with Philips X'Pert-plus (V. 2) software using diffraction patterns file (PDF-2) from ICDD (2011). XPS studies were carried out using a Kratos Axis Ultra DLD spectrometer equipped with a monochromatic $\mathrm{Al} \mathrm{K \alpha X-ray}$ source $(h v=1486.6 \mathrm{eV})$ operating at $150 \mathrm{~W}$, a multichannel plate, and delay line detector; all operated at a base pressure less than $1.0 \times 10^{-9}$ Torr. Survey and high-resolution spectra were collected at fixed analyzer pass energies of 160 and $20 \mathrm{eV}$, respectively. HR-TEM analysis was performed with Titan ST (FEI Co.) operated at $300 \mathrm{kV}$ with a point resolution of $2 \AA$.

\section{Results and Discussion}

Several factors affect the incorporation (doping) of nitrogen into the CNT microstructure including the hydrogen flow rate, growth temperature, and catalyst loading. During injection of the $\mathrm{FcH} / \mathrm{ACN}$ solution at the selected temperature and $\mathrm{H}_{2}$ flow rate, the solvent evaporates and decomposes to produce reactive carbon and nitrogen species, presumably $\mathrm{CH}_{3}{ }^{\bullet}$ and $\mathrm{CN}^{\bullet}$. The catalyst is produced from the decomposition of $\mathrm{FcH}$ into $\mathrm{Fe}$ atoms, which form metallic particles on the inner wall of quartz tube [35]. Cracking or decomposition of the $\mathrm{ACN}$ and $\mathrm{FcH}$ leads to the formation of free radicals, which are transported to the Fe catalyst sites where they adsorb and react to grow N-CNTs [26].

3.1. Morphological and Microstructural Analysis of N-CNTs. The morphological and microstructural characterizations of the N-CNTs were performed using SEM and TEM. Figure 2 displays SEM images of an N-CNT sample deposited 


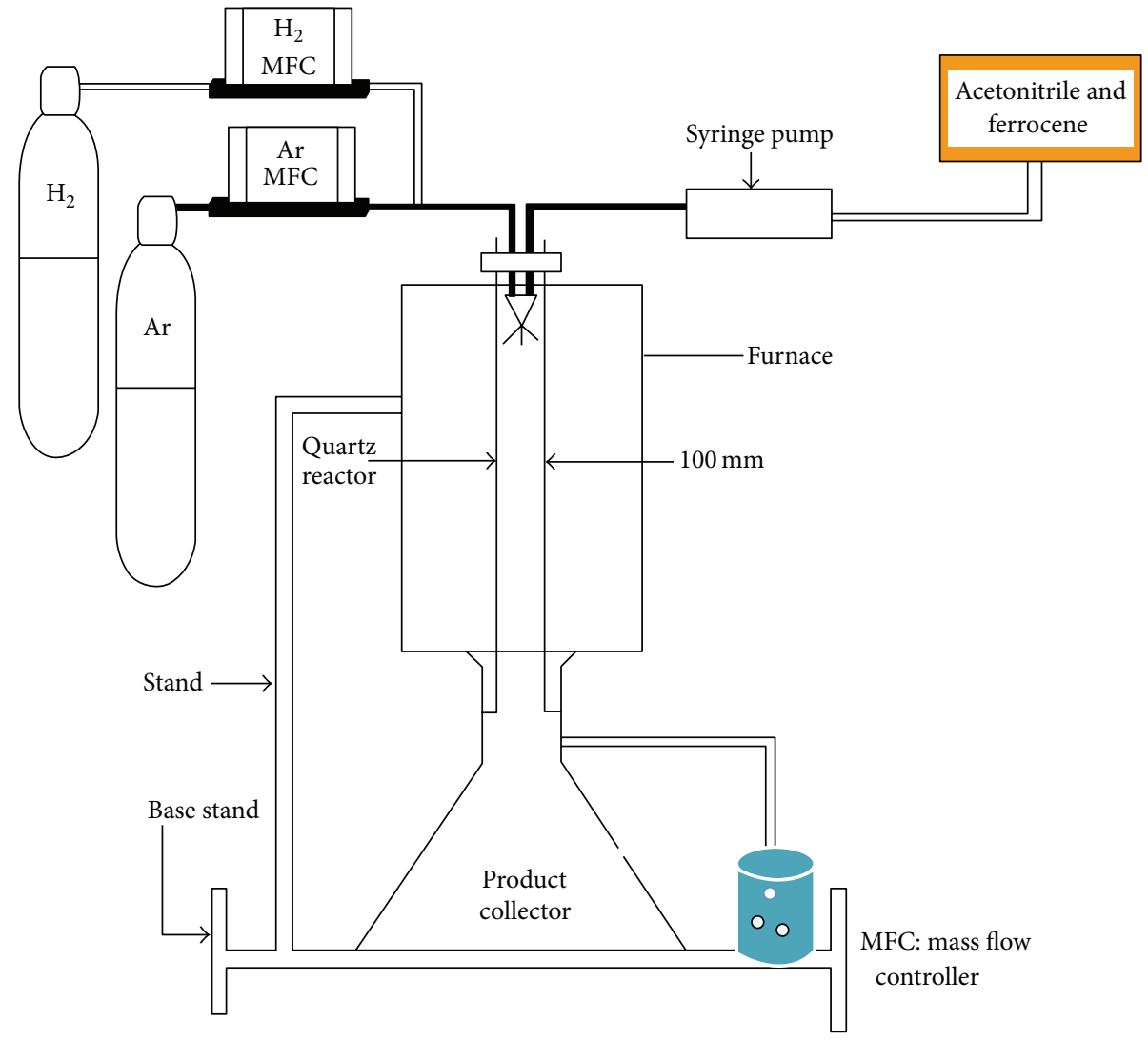

FIGURE 1: Schematic diagram of the IV-CVD reactor used for producing N-CNTs.
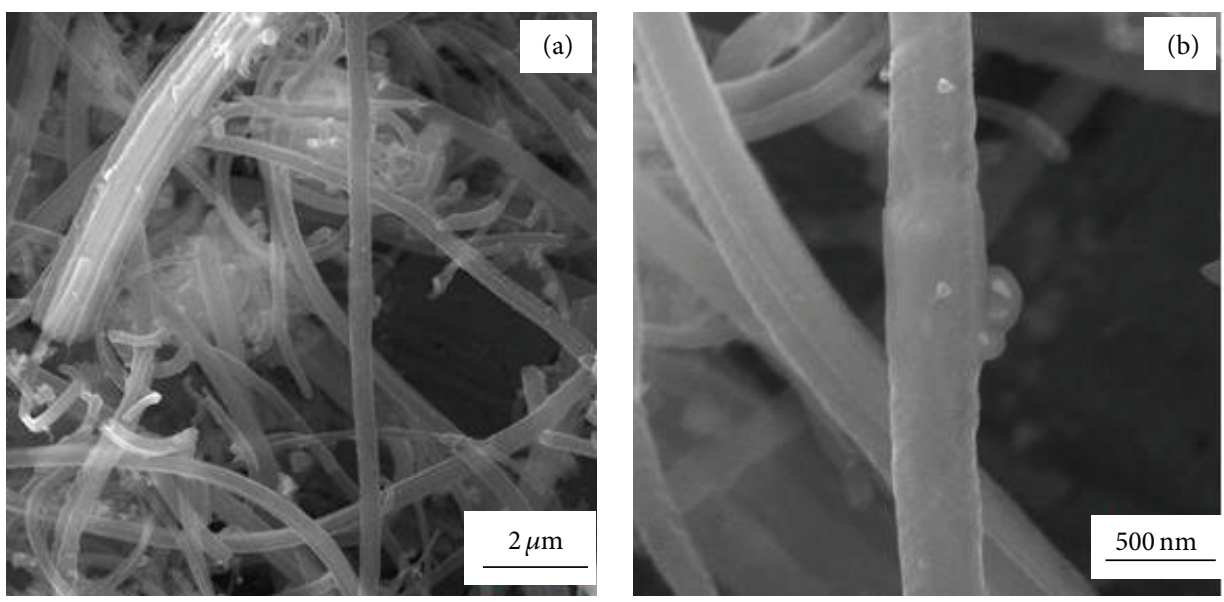

FIGURE 2: SEM micrographs of an N-CNT sample deposited using $5 \mathrm{mg} / \mathrm{mL}$ of FcH/ACN at an $\mathrm{H}_{2}$ flow rate of $1000 \mathrm{~mL} / \mathrm{min}$ and a deposition temperature of $800^{\circ} \mathrm{C}$ for $1 \mathrm{~h}$.

using a $5 \mathrm{mg} / \mathrm{mL} \mathrm{FcH} / \mathrm{ACN}$ solution at an $\mathrm{H}_{2}$ flow rate of $1000 \mathrm{~mL} / \mathrm{min}$ and a deposition temperature of $800^{\circ} \mathrm{C}$. These conditions were selected as a starting point for the optimization based on prior work with this reactor design. It can be seen that the CNTs have a tubular structure with a wide range of diameters from 50 to $300 \mathrm{~nm}$. They were grown as closed-end tubes. HR-TEM images shown in Figure 3 reveal the tubes possess a bamboo-like structure with various numbers of carbon layers (Figure 3(a)). Some tubes are thick consisting of about eight carbon layers (Figure 3(b)). EDS analysis revealed that the N-CNTs primarily consist of carbon and nitrogen with traces of oxygen, silicon (coming from the quartz reactor), and iron (catalyst).

The resulting N-CNTs have a similar size and microstructure as those reported by Lim et al. [27], who used similar deposition conditions but a different catalyst (NiFeMgO) 


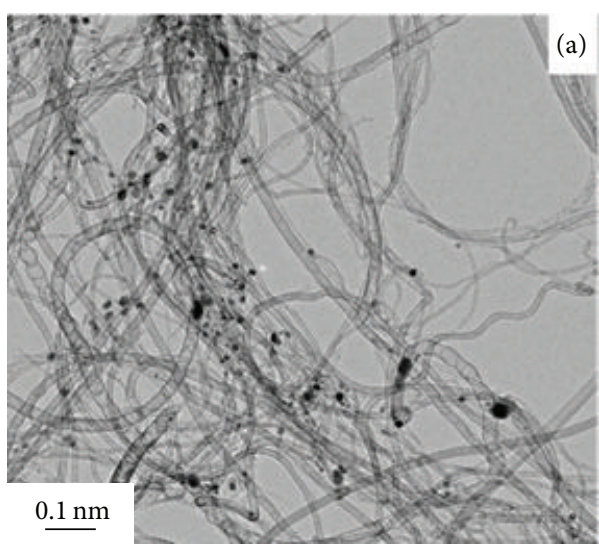

(a)

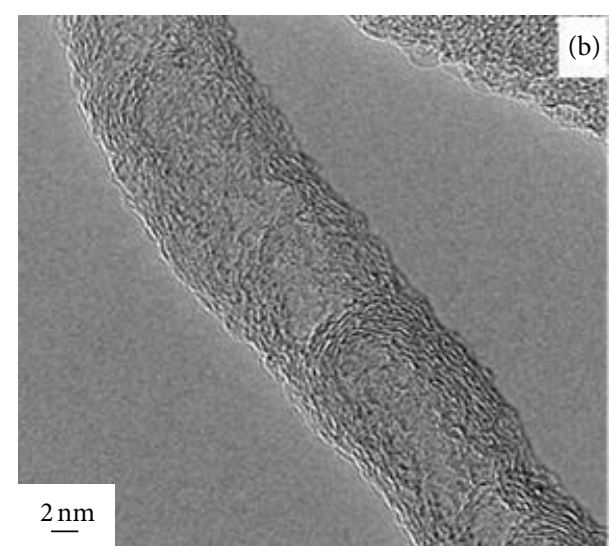

(b)

FIGURE 3: TEM micrographs at (a) low and (b) high magnification of an N-CNT sample deposited using $5 \mathrm{mg} / \mathrm{mL}$ of FcH/ACN at an $\mathrm{H}_{2}$ flow rate of $1000 \mathrm{~mL} / \mathrm{min}$, a deposition temperature of $800^{\circ} \mathrm{C}$, and a deposition time of $1 \mathrm{~h}$. Dark spots are the Fe catalyst particles.

and temperature $\left(400-600^{\circ} \mathrm{C}\right)$. The Fe catalyst particles were randomly distributed throughout the N-CNT network with a size in the range of $8-20 \mathrm{~nm}$ (Figure 3(a)).

3.2. Effect of Hydrogen Flow Rate on the Nitrogen Content in $\mathrm{N}$-CNTs. Figure 4 shows the atomic percentage of nitrogen (measured by EDS) in the N-CNTs as a function of $\mathrm{H}_{2}$ flow rate between 750 and $2000 \mathrm{~mL} / \mathrm{min}$. For these studies, a $5 \mathrm{mg} / \mathrm{mL}$ solution of $\mathrm{FcH} / \mathrm{ACN}$ was used at a deposition temperature of $800^{\circ} \mathrm{C}$. The maximum nitrogen content was obtained at an $\mathrm{H}_{2}$ flow rate of $1000 \mathrm{~mL} / \mathrm{min}$. This result could be linked to the role that $\mathrm{H}_{2}$ plays in the kinetic formation of N-CNTs, specially maintaining the Fe catalyst in the fully reduced form and affecting the availability of the reactive nitrogen and carbon species, $\mathrm{CN}^{*}$ and $\mathrm{CH}_{3}{ }^{\circ}$.

Hao et al. [26] carried out a similar study using a MgOsupported $\mathrm{Fe}$ catalyst and ACN with and without $\mathrm{H}_{2}$. The authors found that the $\mathrm{H}_{2}$ significantly reduced the amount of nitrogen in the CNTs. A reason for this is the formation of $\mathrm{HCN}$ during the pyrolysis of $\mathrm{ACN}$ due to the reaction between $\mathrm{H}_{2}$ and free radicals of $\mathrm{CN}$. The formation of stable $\mathrm{HCN}$ reduces the level of reactive nitrogen species in the gas phase for incorporation. In addition, Lim et al. [27] found that the addition of $\mathrm{H}_{2}$ increased the growth rate of carbon nanofibers (CNFs) when using both acetonitrile and acrylonitrile as the source of carbon. The yield of CNFs with $\mathrm{H}_{2}$ in the reactant gas was 4-8 times higher than that without $\mathrm{H}_{2}$. The presence of $\mathrm{H}_{2}$ makes catalyst surface more active by keeping the $\mathrm{Fe}$ in the fully reduced form. Under their deposition conditions, no more than 5 at.\% of nitrogen was achieved when $\mathrm{H}_{2}$ was introduced, while in the absence of $\mathrm{H}_{2}$ the nitrogen content increased to 10 at.\%. In our experiments, the maximum nitrogen content obtained was 14 at. $\%$ at $800^{\circ} \mathrm{C}, 1000 \mathrm{~mL} / \mathrm{min}$ of $\mathrm{H}_{2}$ and $5 \mathrm{mg} / \mathrm{mL}$ of $\mathrm{FcH} / \mathrm{ACN}$. This doping level is significantly higher than that reported by Lim et al. [27], who used the similar growth conditions but with a horizontal fixed-bed reactor.

The mass of N-CNTs (Figure 4) collected as a function of the $\mathrm{H}_{2}$ flow rate. The results reveal an increasing mass

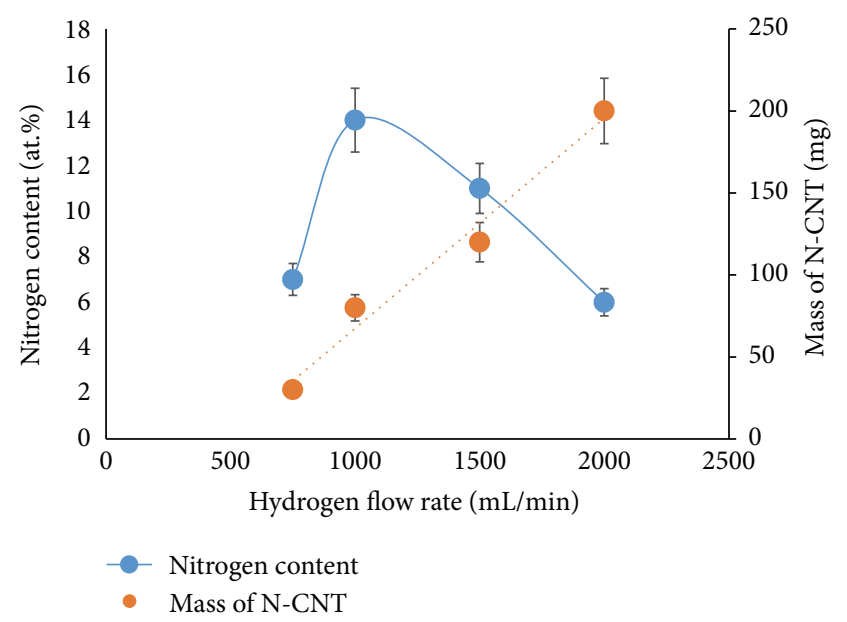

FIGURE 4: Effect of $\mathrm{H}_{2}$ flow rate on the nitrogen content and mass $\mathrm{N}$-CNTs deposited with $5 \mathrm{mg} / \mathrm{mL}$ of $\mathrm{FcH} / \mathrm{ACN}$ at $800^{\circ} \mathrm{C}$ for $1 \mathrm{~h}$.

with increasing $\mathrm{H}_{2}$ flow rate. From the data, a production rate of around $100 \mathrm{mg} / \mathrm{h}$ is calculated at $1000 \mathrm{~mL} / \mathrm{min}$. The production rate in this vertical reactor was measured by the amount of N-CNTs collected from the wall of the reactor and the collector placed at the bottom of the reactor for a fixed reaction time. This trend is in agreement with the work of van Dommele et al. [38] and Wasel et al. [39] for undoped CNTs. The increasing flow rate of $\mathrm{H}_{2}$ leading to a higher production rate may be due to (i) reduced soot formation on the catalyst that would inactivate it and (ii) maintaining Fe catalyst in its fully reduced and most active form.

3.3. Effect of Temperature on the Nitrogen Content. The growth temperature is another key parameter in the production of N-CNTs $[31,40]$. It plays a critical role in the decomposition of $\mathrm{FcH}$ above $500^{\circ} \mathrm{C}[3,41]$ leading to the formation of Fe nanoparticles that grow in size by particle collisions [42]. Ayala et al. [41] suggested that when the growth temperature is increased, Fe particles sinter together 


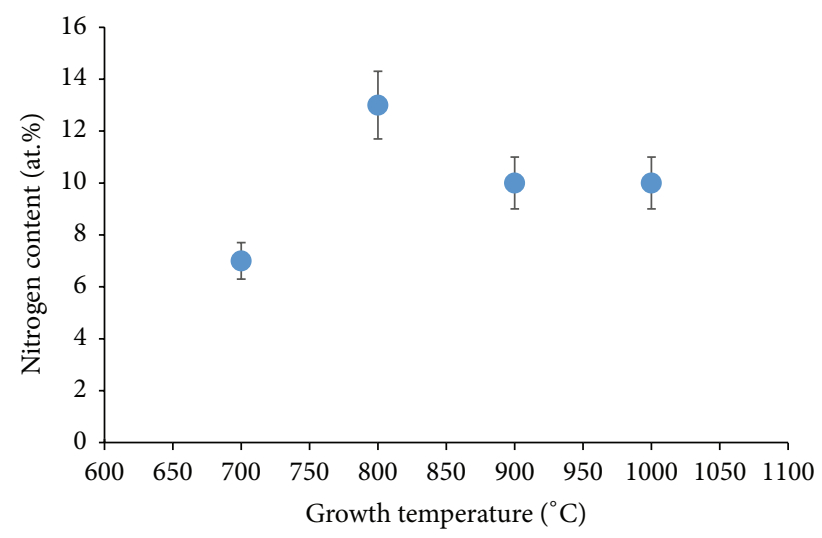

FIGURE 5: Effect of growth temperature on the nitrogen content in N-CNTs at $1000 \mathrm{~mL} / \mathrm{min}$ of $\mathrm{H}_{2}$ and $5 \mathrm{mg} / \mathrm{mL}$ of $\mathrm{FcH} / \mathrm{ACN}$ and deposition time of $1 \mathrm{~h}$.

producing larger nanoparticles, leading to the formation of larger diameter nanotubes. The growth temperature also affects the availability of reactive carbon species from the decomposition of ACN. Figure 5 shows the atomic percentage of nitrogen in the N-CNTs as a function of growth temperature. It can be concluded that the temperature of maximum nitrogen incorporation is near $800^{\circ} \mathrm{C}$. The effect of deposition temperature on the nitrogen doping of CNTs is somewhat inconsistent with the literature. For example, Lee et al. [2] showed that the incorporation of nitrogen varies inversely with the growth temperature particularly at high temperatures. They observed that the percentage of nitrogen decreased by $30 \%$ when the deposition temperature was increased from 800 to $1000^{\circ} \mathrm{C}$. In the other work, Koós et al. [24] reported the nitrogen content decreased by nearly $50 \%$ when increasing the temperature from 800 to $900^{\circ} \mathrm{C}$. In our work, we only saw a few percent reduction when the deposition temperature was increased from 800 to $1000^{\circ} \mathrm{C}$.

\subsection{Effect of Catalyst Concentration on the Nitrogen Content} in $\mathrm{N}$-CNTs. These studies were performed with various $\mathrm{FcH}$ concentrations in ACN from 2 to $15 \mathrm{mg} / \mathrm{mL}$ while maintaining a constant growth temperature of $800^{\circ} \mathrm{C}$ and an $\mathrm{H}_{2}$ flow rate of $1000 \mathrm{~mL} / \mathrm{min}$. As illustrated in Figure 6, the highest amount of nitrogen incorporation was obtained when the $\mathrm{FcH}$ concentrations were in the range of $2.5-5 \mathrm{mg} / \mathrm{mL}$. The EDS results revealed a maximum $\mathrm{N}$ content of 14.5 at.\%. As the concentration was increased, the nitrogen content decreased to about 10 at.\%. It is clear that the nitrogen content varied over a relatively narrow range from 10 to 15 at.\% at different $\mathrm{FcH}$ concentrations. As the $\mathrm{FcH}$ concentration is increased, the N/C atomic ratio in the source gas decreases, which could be the cause for the decreasing nitrogen content in the CNTs.

\subsection{Chemical and Structural Characterization of the N-CNTs.} Figure 7 shows XRD patterns of N-CNT and CNT samples. The N-CNTs were deposited using $5 \mathrm{mg} / \mathrm{mL}$ of FcH/ACN, an $\mathrm{H}_{2}$ flow rate of $1000 \mathrm{~mL} / \mathrm{min}$, and a deposition temperature

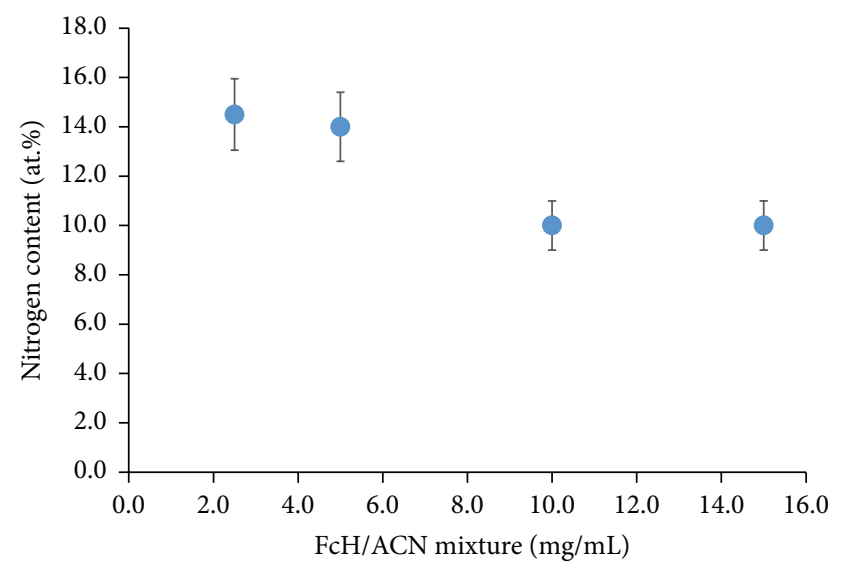

FIGURE 6: Effect of the Fe catalyst concentration on the nitrogen content in $\mathrm{N}$-CNTs grown at an $\mathrm{H}_{2}$ flow rate of $1000 \mathrm{~mL} / \mathrm{min}$, a deposition temperature of $800^{\circ} \mathrm{C}$, and a deposition time of $1 \mathrm{~h}$.

TABLE 1: XPS determined elemental composition of N-CNTs (at.\%) for low and high catalyst loadings.

\begin{tabular}{lccccc}
\hline Elements (at.\%) & $\mathrm{Fe}$ & $\mathrm{O}$ & $\mathrm{C}$ & $\mathrm{N}$ & $\mathrm{Si}$ \\
\hline $\begin{array}{l}\text { Low catalyst loading } \\
(5 \mathrm{mg} / \mathrm{mL})\end{array}$ & 0.6 & 3 & 92 & 3.8 & 1.3 \\
$\begin{array}{l}\text { High catalyst loading } \\
(15 \mathrm{mg} / \mathrm{mL})\end{array}$ & 0.3 & 2 & 94 & 3.1 & 0.4 \\
\hline
\end{tabular}

of $800^{\circ} \mathrm{C}$, while the CNTs were deposited under identical conditions except that an FcH/para-xylene solution was used as the source of carbon. The deposition time for both samples was $1 \mathrm{~h}$. It is worth noting that XRD data for the N-CNTs samples were similar regardless of the catalyst concentration, growth temperature, or $\mathrm{H}_{2}$ flow rate used. The peak at $2 \theta=$ $27.17^{\circ}$ is the characteristic of (002) line for hexagonal graphite $(d=3.27 \AA)$ arising from the N-CNT carbon microstructure. This peak reflects the graphitic character of the CNTs. The peak in $42-48^{\circ}$ range could be attributed to (101) plane of $\mathrm{N}$-CNTs or to some trace of iron carbide or iron metallic catalyst. However, because of the presence of many nitrogen functionalities in the N-CNT microstructure, there is a small shift $\left(\Delta 2 \theta=0.945^{\circ}\right)$ towards higher $2 \theta$ as compared to the diffraction data for nitrogen-free CNTs $\left(2 \theta=26.71^{\circ}\right)$. This may be due to the incorporation of nitrogen in the structure of nanotubes that promotes the graphitic stacking and creates slight distortion in crystalline regularity along a or b direction by shorter C-N bonds [27].

XPS has been proven useful for quantifying the level and identifying the chemical environments of the incorporated nitrogen [4, 43-46]. Figures 8 and 9 show typical N1s XPS spectra between 394 and $410 \mathrm{eV}$ for $\mathrm{N}-\mathrm{CNT}$ samples grown with a low $(5 \mathrm{mg} / \mathrm{mL})$ and high $(15 \mathrm{mg} / \mathrm{mL})$ concentration of $\mathrm{FcH} / \mathrm{ACN}$ at a growth temperature of $800^{\circ} \mathrm{C}$.

The data analysis (see Table 1) showed that 3.8 and 3.1 at.\% of nitrogen were incorporated into the N-CNTs at the low and high catalyst loadings, respectively. It is important to note that the amount of nitrogen determined by XPS (3.1-3.8 at.\%) is lower than the values obtained with EDS (10-14 at.\%), due to 


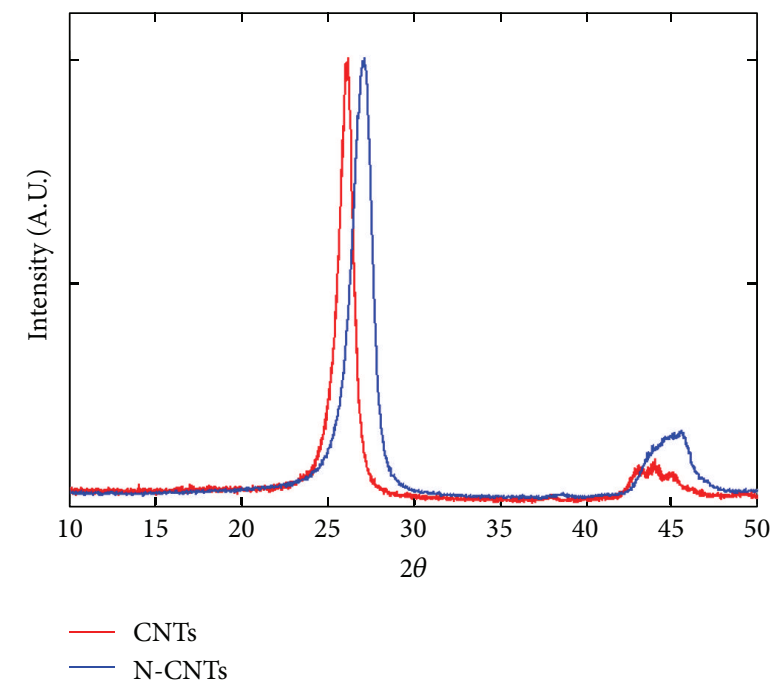

FIGURE 7: XRD patterns of CNTs (red) deposited using $5 \mathrm{mg} / \mathrm{mL}$ of $\mathrm{FcH} /$ para-xylene and N-CNTs (blue) deposited with $5 \mathrm{mg} / \mathrm{mL}$ of $\mathrm{FcH} / \mathrm{ACN}$ using the IV-CVD reactor. For both samples, the $\mathrm{H}_{2}$ flow rate was $1000 \mathrm{~mL} / \mathrm{min}$, the deposition temperature was $800^{\circ} \mathrm{C}$, and the deposition time was $1 \mathrm{~h}$.

the fact that XPS is a surface sensitive technique providing elemental composition from a depth of 1-12 nm, while the depth in EDS is greater than $500 \mathrm{~nm}$. Nevertheless, a similar trend is observed with both analysis techniques; that is, the percentage of nitrogen incorporated decreases with catalyst loading. Si and Fe impurities were also detected in both samples.

Nitrogen in four different chemical environments was identified in the N-CNTs with the relative ratio of the types depending on the concentration of $\mathrm{FcH}$ catalyst used. It has been reported that at least four types of nitrogen can be distinguished based on deconvolution of the N1s spectrum: pyridinic- $\mathrm{N}(398.6 \mathrm{eV})$, pyrrolic- $\mathrm{N}(400.1 \mathrm{eV})$, quaternary- $\mathrm{N}$ $(401.1 \mathrm{eV})$, and pyridinic-N oxides $(402-405 \mathrm{eV})[14,17,36$, $40,41,47]$. The literature peaks agree well with those seen in the deconvoluting of our spectra. As displayed in Figures 8 and 9 , the distribution of the different types of nitrogen functional groups depends on the catalyst concentration/loading. Indeed, it should be noted that there are seven peaks in the low catalyst sample spectrum (Figure 8) and only four peaks in the high catalyst sample (Figure 9). In addition to the pyridinic, pyrrolic, quaternary, and pyridinic oxides nitrogen species, Kumar [31] detected more than six peaks of nitrogen species in the pyrolysis of mixtures of camphor, $\mathrm{FcH}$, and dimethylformamide. They attributed the peak at $397.3 \mathrm{eV}$ to the iron nitride in agreement with the results found by $\mathrm{He}$ et al. [16] and Hasan et al. [48]. The latter group assigned the N1s peak at $398.1 \mathrm{eV}$ to the interaction between metal and pyridinic nitrogen. On the other hand, Ronning et al. [44] have reported the most nitrogen functional group forms present in carbonaceous materials and assigned the peak at 399.5 to pyrrolic or cyano-like groups and the peaks at (402.5$406.1 \mathrm{eV}$ ) to certain forms of oxidized nitrogen, like $\mathrm{N}$-oxides of pyridinic-N. These results are, however, in contrast to

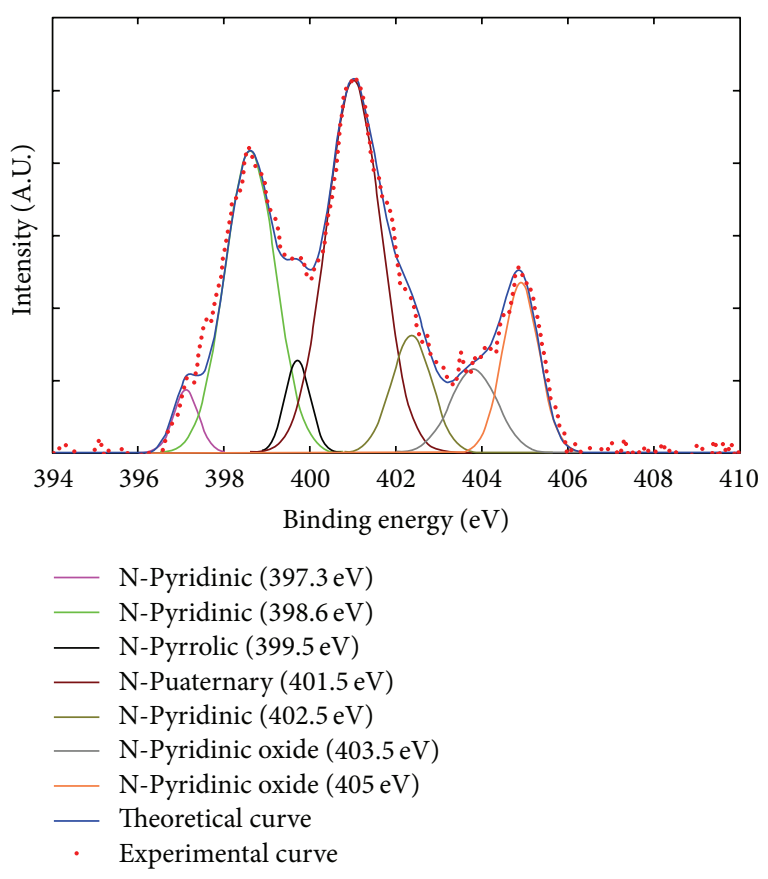

FIGURE 8: Deconvoluted XPS spectrum in the N1s region of an NCNT sample grown with an $\mathrm{FcH} / \mathrm{ACH}$ concentration of $5 \mathrm{mg} / \mathrm{mL}$ and $1000 \mathrm{~mL} / \mathrm{min}$ of $\mathrm{H}_{2}$ at $800^{\circ} \mathrm{C}$ using the IV-CVD reactor.

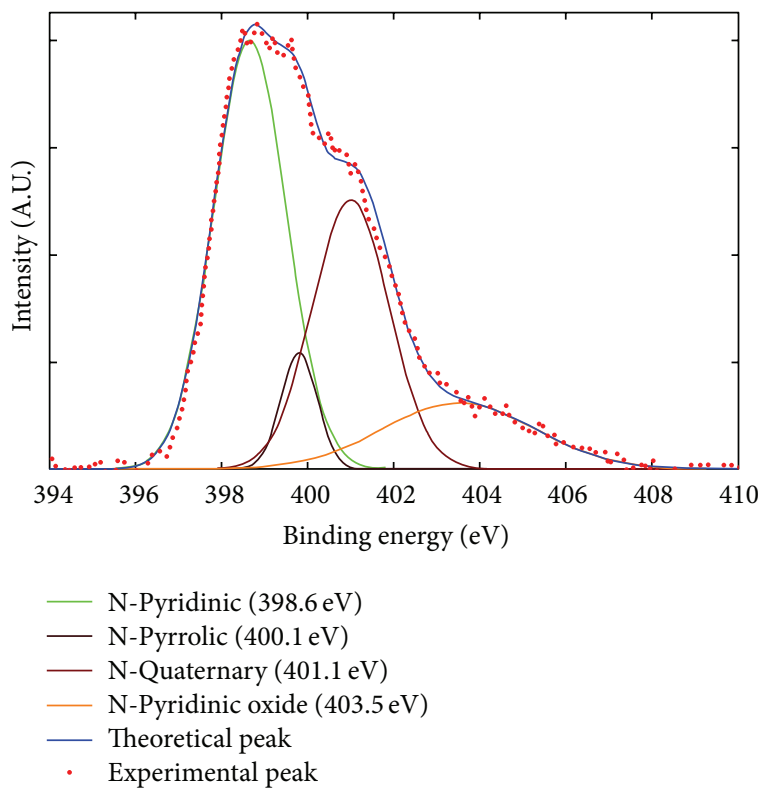

FIGURE 9: Deconvoluted XPS spectrum in the N1s region for an NCNT sample grown with an FcH/ACH concentration of $15 \mathrm{mg} / \mathrm{mL}$ and $1000 \mathrm{~mL} / \mathrm{min}$ of $\mathrm{H}_{2}$ at $800^{\circ} \mathrm{C}$ using the IV-CVD reactor.

other reports [31, 47] that attribute the peaks at 403.3 and $404.3 \mathrm{eV}$ to the molecular nitrogen trapped inside the tubes or intercalated into the graphite layers of the CNTs.

The formation of pyridinic oxides in our samples could be explained by the high reactivity towards oxidation via the transformation of quaternary nitrogen to pyridinic oxides at 
TABLE 2: Major nitrogen functional groups identified in the N-CNTs grown with the low and high catalyst loadings.

\begin{tabular}{lcccc}
\hline Sample/N content $(\%)$ & $\begin{array}{c}\text { N-Pyridinic } \\
(397-398.6 \mathrm{eV})\end{array}$ & $\begin{array}{c}\text { N-Pyrrolic } \\
(399.7 \mathrm{eV})\end{array}$ & $\begin{array}{c}\text { N-Quaternary } \\
(401 \mathrm{eV})\end{array}$ & $\begin{array}{c}\text { N-Pyridinic oxides } \\
(402-405 \mathrm{eV})\end{array}$ \\
\hline Low catalyst loading $(5 \mathrm{mg} / \mathrm{mL})$ & 31 & 5 & 37 & 28 \\
High catalyst loading $(15 \mathrm{mg} / \mathrm{mL})$ & 48 & 7 & 31 & 15 \\
\hline
\end{tabular}

high temperatures [40] in presence of oxygen traces dissolved in the mixture or impurities in the reactor. Table 2 compares the percentage of $\mathrm{N}$-types incorporated into CNTs structure obtained from deconvolution and fitting results.

The comparison shows that the percentages of N-pyridinic and N-pyrrolic functionalities tend to increase and $\mathrm{N}$ quaternary and $\mathrm{N}$-pyridinic oxides groups tend to decrease with catalyst loading at the same growth temperature. It has been found that the dilution of nitrogen source affects the formation of nitrogen species. Ghosh et al. [32] injected different dimethylformamide concentrations in the presence of $\mathrm{FcH}$ and found that the peak areas of pyridinic, pyrrolic, and quaternary species increased with concentration of nitrogen source but at the same catalyst loading. However, in our study, the catalyst loading was increased leading to an increase in percentage of pyridinic and pyrrolic and decrease in quaternary and pyridinic oxides nitrogen species. Thus, we assume that increasing catalyst loading could promote the formation of N-pyridinic.

\section{Conclusions}

Nitrogen-doped carbon nanotubes were synthesized using a mixture of $\mathrm{FcH}$ and $\mathrm{ACN}$ in an inverted-vertical CVD reactor. The primary aim of this study was optimization of the synthesis parameters to prepare N-CNTs with high nitrogen content. Specifically, the effects of the synthesis conditions including hydrogen flow rate, growth temperature, and catalyst concentration were evaluated. The results showed that $\mathrm{N}-$ CNTs could be produced in an inverted-vertical CVD reactor with a high nitrogen incorporation of around 14 at.\% using 2.5 to $5 \mathrm{mg} / \mathrm{mL}$ of $\mathrm{FcH} / \mathrm{ACN}$ solution, a hydrogen flow rate of $1000 \mathrm{~mL} / \mathrm{min}$, and deposition temperature of $800^{\circ} \mathrm{C}$. TEM images revealed that the N-CNTs have a bamboo-like structure consistent with the insertion of heteroatoms into the lattice. XRD patterns for the N-CNTs, as compared to CNTs with no nitrogen, revealed a shift toward lower $d$-spacing due to the formation of shorter N-C bonds as compared to C$\mathrm{C}$ bonds. The former leads to less graphene sheet stacking. XPS was used to elucidate the effect of catalyst loading on the formation of different types of nitrogen in the CNTs structure. The results showed that nitrogen in four different chemical environments was formed when a high catalyst loading was employed while seven nitrogen types were found at a low catalyst loading. Finally, the results showed that the percentages of $\mathrm{N}$-pyridinic and $\mathrm{N}$-pyrrolic moieties increase and $\mathrm{N}$-quaternary and $\mathrm{N}$-pyridinic decrease with increased catalyst loading at the same deposition temperature. With the deposition parameters optimized for producing N-CNTs with a high nitrogen content, future work will involve scaling up of the IV-CVD reactor for mass production as well as more detailed investigation of the N-CNT growth mechanism.

\section{Conflict of Interests}

The authors declare that there is no conflict of interests regarding the publication of this paper.

\section{Acknowledgments}

The authors acknowledge the support provided by King Abdulaziz City for Science and Technology (KACST), Riyadh, KSA, through the Science \& Technology Unit at Deanship of Scientific Research, King Fahd University of Petroleum \& Minerals (KFUPM), Dhahran, KSA, for funding this work through Project no. 10-ENE1375-04 as part of the National Science, Technology, and Innovation Plan.

\section{References}

[1] Y.-T. Jang, J.-H. Ahn, Y.-H. Lee, and B.-K. Ju, "Effect of $\mathrm{NH}_{3}$ and thickness of catalyst on growth of carbon nanotubes using thermal chemical vapor deposition," Chemical Physics Letters, vol. 372, no. 5-6, pp. 745-749, 2003.

[2] Y. T. Lee, N. S. Kim, S. Y. Bae et al., "Growth of vertically aligned nitrogen-doped carbon nanotubes: control of the nitrogen content over the temperature range $900-1100{ }^{\circ} \mathrm{C}$," The Journal of Physical Chemistry B, vol. 107, no. 47, pp. 12958-12963, 2003.

[3] A. Moisala, A. G. Nasibulin, D. P. Brown, H. Jiang, L. Khriachtchev, and E. I. Kauppinen, "Single-walled carbon nanotube synthesis using ferrocene and iron pentacarbonyl in a laminar flow reactor," Chemical Engineering Science, vol. 61, no. 13, pp. 4393-4402, 2006.

[4] T. Belz, A. Bauer, J. Find et al., "Structural and chemical characterization of N-doped nanocarbons," Carbon, vol. 36, no. 5-6, pp. 731-741, 1998.

[5] S. Esconjauregui, S. Bhardwaj, J. Yang et al., "Carbon nanotube growth on conductors: influence of the support structure and catalyst thickness," Carbon, vol. 73, pp. 13-24, 2014.

[6] H. Dai, A. G. Rinzler, P. Nikolaev, A. Thess, D. T. Colbert, and R. E. Smalley, "Single-wall nanotubes produced by metalcatalyzed disproportionation of carbon monoxide," Chemical Physics Letters, vol. 260, no. 3-4, pp. 471-475, 1996.

[7] E. Flahaut, A. Govindaraj, A. Peigney, C. Laurent, A. Rousset, and C. N. R. Rao, "Synthesis of single-walled carbon nanotubes using binary (Fe, $\mathrm{Co}, \mathrm{Ni}$ ) alloy nanoparticles prepared in situ by the reduction of oxide solid solutions," Chemical Physics Letters, vol. 300, no. 1-2, pp. 236-242, 1999.

[8] R. Sen, A. Govindaraj, and C. N. R. Rao, "Carbon nanotubes by the metallocene route," Chemical Physics Letters, vol. 267, no. 3-4, pp. 276-280, 1997. 
[9] R. Andrews, D. Jacques, A. M. Rao et al., "Continuous production of aligned carbon nanotubes: a step closer to commercial realization," Chemical Physics Letters, vol. 303, no. 5-6, pp. 467474, 1999.

[10] E. Couteau, K. Hernadi, J. W. Seo et al., "CVD synthesis of highpurity multiwalled carbon nanotubes using $\mathrm{CaCO}_{3}$ catalyst support for large-scale production," Chemical Physics Letters, vol. 378, no. 1-2, pp. 9-17, 2003.

[11] M. J. Bronikowski, P. A. Willis, D. T. Colbert, K. A. Smith, and R. E. Smalley, "Gas-phase production of carbon single-walled nanotubes from carbon monoxide via the HiPco process: a parametric study," Journal of Vacuum Science \& Technology A, vol. 19, no. 4, pp. 1800-1805, 2001.

[12] Y.-L. Li, I. A. Kinloch, and A. H. Windle, "Direct spinning of carbon nanotube fibers from chemical vapor deposition synthesis," Science, vol. 304, no. 5668, pp. 276-278, 2004.

[13] P. Mauron, C. Emmenegger, P. Sudan, P. Wenger, S. Rentsch, and A. Züttel, "Fluidised-bed CVD synthesis of carbon nanotubes on $\mathrm{Fe}_{2} \mathrm{O}_{3} / \mathrm{MgO}$," Diamond and Related Materials, vol. 12, no. 37, pp. 780-785, 2003.

[14] M. I. Ionescu, Y. Zhang, R. Li, H. Abou-Rachid, and X. Sun, "Nitrogen-doping effects on the growth structure and electrical performance of carbon nanotubes obtained by spray pyrolysis," Applied Surface Science, vol. 258, pp. 4563-4568, 2012.

[15] R. Sen, B. C. Satishkumar, A. Govindaraj et al., "B-C-N, C$\mathrm{N}$ and $\mathrm{B}-\mathrm{N}$ nanotubes produced by the pyrolysis of precursor molecules over Co catalysts," Chemical Physics Letters, vol. 287, no. 5-6, pp. 671-676, 1998.

[16] D. He, Y. Jiang, H. Lv, M. Pan, and S. Mu, "Nitrogen-doped reduced graphene oxide supports for noble metal catalysts with greatly enhanced activity and stability," Applied Catalysis B: Environmental, vol. 132-133, pp. 379-388, 2013.

[17] P. H. Matter, L. Zhang, and U. S. Ozkan, "The role of nanostructure in nitrogen-containing carbon catalysts for the oxygen reduction reaction," Journal of Catalysis, vol. 239, no. 1, pp. 8396, 2006.

[18] B. Merzougui, A. Hachimi, A. Akinpelu, S. Bukola, and M. Shao, "A Pt-free catalyst for oxygen reduction reaction based on Fe-N multiwalled carbon nanotube composites," Electrochimica Acta, vol. 107, pp. 126-132, 2013.

[19] Y. Cao, H. Yu, J. Tan et al., "Nitrogen-, phosphorous- and borondoped carbon nanotubes as catalysts for the aerobic oxidation of cyclohexane," Carbon, vol. 57, pp. 433-442, 2013.

[20] L. Chen, K. Xia, L. Huang, L. Li, L. Pei, and S. Fei, "Facile synthesis and hydrogen storage application of nitrogen-doped carbon nanotubes with bamboo-like structure," International Journal of Hydrogen Energy, vol. 38, no. 8, pp. 3297-3303, 2013.

[21] M. Vikkisk, I. Kruusenberg, U. Joost, E. Shulga, and K. Tammeveski, "Electrocatalysis of oxygen reduction on nitrogencontaining multi-walled carbon nanotube modified glassy carbon electrodes," Electrochimica Acta, vol. 87, pp. 709-716, 2013.

[22] C. Yu, Y. Wang, Y. Liu, C. Guo, and Y. Hu, "Facile growth of ZnO nanocrystals on nitrogen-doped carbon nanotubes for visiblelight photodegradation of dyes," Materials Letters, vol. 100, pp. 278-281, 2013.

[23] S. Boncel, S. W. Pattinson, V. Geiser, M. S. P. Shaffer, and K. K. K. Koziol, "En route to controlled catalytic CVD synthesis of densely packed and vertically aligned nitrogen-doped carbon nanotube arrays," Beilstein Journal of Nanotechnology, vol. 5, no. 1, pp. 219-233, 2014.

[24] A. A. Koós, F. Dillon, E. A. Obraztsova, A. Crossley, and N. Grobert, "Comparison of structural changes in nitrogen and boron-doped multi-walled carbon nanotubes," Carbon, vol. 48, no. 11, pp. 3033-3041, 2010.

[25] R. M. Yadav, P. S. Dobal, T. Shripathi, R. S. Katiyar, and O. N. Srivastava, "Effect of growth temperature on bamboo-shaped carbon-nitrogen $(\mathrm{C}-\mathrm{N})$ nanotubes synthesized using ferrocene acetonitrile precursor," Nanoscale Research Letters, vol. 4, no. 3, pp. 197-203, 2008.

[26] Y. Hao, L. Qingwen, Z. Jin, and L. Zhongfan, "The effect of hydrogen on the formation of nitrogen-doped carbon nanotubes via catalytic pyrolysis of acetonitrile," Chemical Physics Letters, vol. 380, no. 3-4, pp. 347-351, 2003.

[27] S. Lim, S.-H. Yoon, I. Mochida, and J. Doo-Hwan, "Direct synthesis and structural analysis of nitrogen-doped carbon nanofibers," Langmuir, vol. 25, no. 14, pp. 8268-8273, 2009.

[28] M. Nath, B. C. Satishkumar, A. Govindaraj, C. P. Vinod, and C. N. R. Rao, "Production of bundles of aligned carbon and carbon-nitrogen nanotubes by the pyrolysis of precursors on silica-supported iron and cobalt catalysts," Chemical Physics Letters, vol. 322, no. 5, pp. 333-340, 2000.

[29] N. Grobert, M. Terrones, S. Trasobares et al., "Novel route to aligned nanotubes and nanofibres using laser-patterned catalytic substrates," Applied Physics A, vol. 70, no. 2, pp. 175$183,2000$.

[30] R. Che, L.-M. Peng, Q. Chen, X. F. Duan, and Z. N. Gu, " $\mathrm{Fe}_{2} \mathrm{O}_{3}$ particles encapsulated inside aligned $\mathrm{CN}_{\mathrm{x}}$ nanotubes," Applied Physics Letters, vol. 82, no. 19, pp. 3319-3321, 2003.

[31] M. Kumar, "Carbon nanotube synthesis and growth mechanism," in Carbon Nanotubes-Synthesis, Characterization, Applications, S. Yellampalli, Ed., chapter 8, InTech, Rijeka, Croatia, 2011.

[32] K. Ghosh, M. Kumar, T. Maruyama, and Y. Ando, "Tailoring the field emission property of nitrogen-doped carbon nanotubes by controlling the graphitic/pyridinic substitution," Carbon, vol. 48, no. 1, pp. 191-200, 2010.

[33] Y. T. Lee, N. S. Kim, J. Park et al., “Temperature-dependent growth of carbon nanotubes by pyrolysis of ferrocene and acetylene in the range between 700 and $1000{ }^{\circ} \mathrm{C}$," Chemical Physics Letters, vol. 372, no. 5-6, pp. 853-859, 2003.

[34] C. N. R. Rao and A. Govindaraj, "Carbon nanotubes from organometallic precursors," Accounts of Chemical Research, vol. 35, no. 12, pp. 998-1007, 2002.

[35] J. Zhang, R. Tu, and T. Goto, "Preparation of carbon nanotube by rotary $\mathrm{CVD}$ on $\mathrm{Ni}$ nano-particle precipitated $\mathrm{CBN}$ using nickelocene as a precursor," Materials Letters, vol. 65, no. 2, pp. 367-370, 2011.

[36] E. J. Biddinger, D. V. Deak, and U. S. Ozkan, "Nitrogen-containing carbon nanostructures as oxygen-reduction catalysts," Topics in Catalysis, vol. 52, no. 11, pp. 1566-1574, 2009.

[37] E. N. Nxumalo and N. J. Coville, "Nitrogen-doped carbon nanotubes from organometallic compounds: a review," Materials, vol. 3, no. 3, pp. 2141-2171, 2010.

[38] S. van Dommele, A. Romero-Izquirdo, R. Brydson, K. P. de Jong, and J. H. Bitter, "Tuning nitrogen functionalities in catalytically grown nitrogen-containing carbon nanotubes," Carbon, vol. 46, no. 1, pp. 138-148, 2008.

[39] W. Wasel, K. Kuwana, P. T. A. Reilly, and K. Saito, "Experimental characterization of the role of hydrogen in CVD synthesis of MWCNTs," Carbon, vol. 45, no. 4, pp. 833-838, 2007.

[40] M. Pérez-Cabero, E. Romeo, C. Royo, A. Monzón, A. GuerreroRuíz, and I. Rodríguez-Ramos, "Growing mechanism of CNTs: a kinetic approach," Journal of Catalysis, vol. 224, no. 1, pp. 197205, 2004. 
[41] P. Ayala, A. Grüneis, C. Kramberger et al., "Effects of the reaction atmosphere composition on the synthesis of single and multiwalled nitrogen-doped nanotubes," Journal of Chemical Physics, vol. 127, no. 18, Article ID 184709, 2007.

[42] D. Conroy, A. Moisala, S. Cardoso, A. Windle, and J. Davidson, "Carbon nanotube reactor: ferrocene decomposition, iron particle growth, nanotube aggregation and scale-up," Chemical Engineering Science, vol. 65, no. 10, pp. 2965-2977, 2010.

[43] H. Koch, P. Jørgensen, and T. Helgaker, "The molecular structure of ferrocene," Journal of Chemical Physics, vol. 104, no. 23, pp. 9528-9530, 1996.

[44] C. Ronning, H. Feldermann, R. Merk, H. Hofsäss, P. Reinke, and J.-U. Thiele, "Carbon nitride deposited using energetic species: a review on XPS studies," Physical Review B, vol. 58, no. 4, article 2207, 1998.

[45] J. R. Pels, F. Kapteijn, J. A. Moulijn, Q. Zhu, and K. M. Thomas, "Evolution of nitrogen functionalities in carbonaceous materials during pyrolysis," Carbon, vol. 33, no. 11, pp. 1641-1653, 1995.

[46] E. Raymundo-Piñero, D. Cazorla-Amorós, A. Linares-Solano, J. Find, U. Wild, and R. Schlögl, "Structural characterization of N-containing activated carbon fibers prepared from a low softening point petroleum pitch and a melamine resin," Carbon, vol. 40, no. 4, pp. 597-608, 2002.

[47] A. Adenier, M. M. Chehimi, I. Gallardo, J. Pinson, and N. Vilà, "Electrochemical oxidation of aliphatic amines and their attachment to carbon and metal surfaces," Langmuir, vol. 20, no. 19, pp. 8243-8253, 2004.

[48] S. A. Hasan, E. K. Tsekoura, V. Sternhagen, and M. Strømme, "Evolution of the composition and suspension performance of nitrogen-doped graphene," Journal of Physical Chemistry C, vol. 116, no. 11, pp. 6530-6536, 2012. 

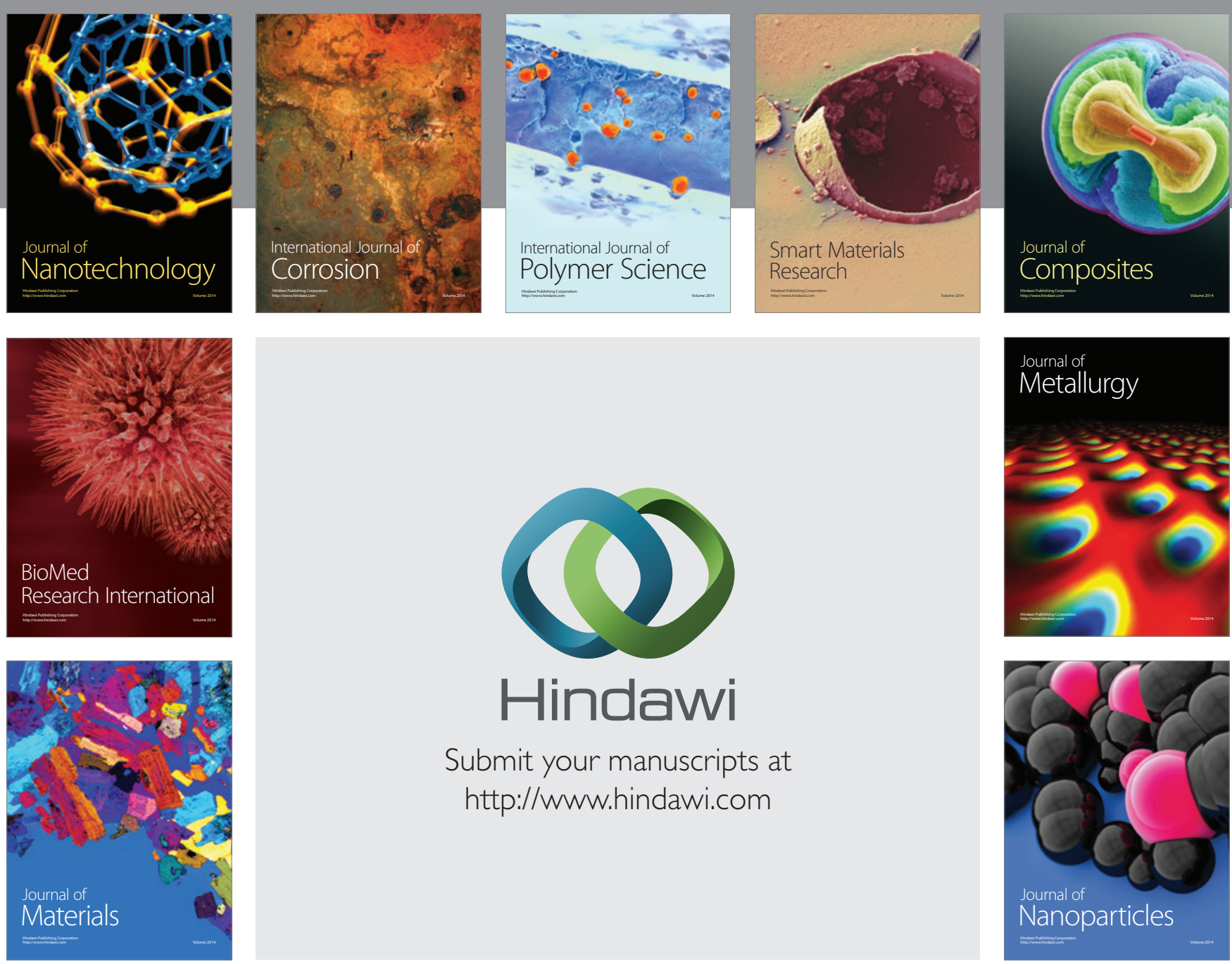

Submit your manuscripts at http://www.hindawi.com
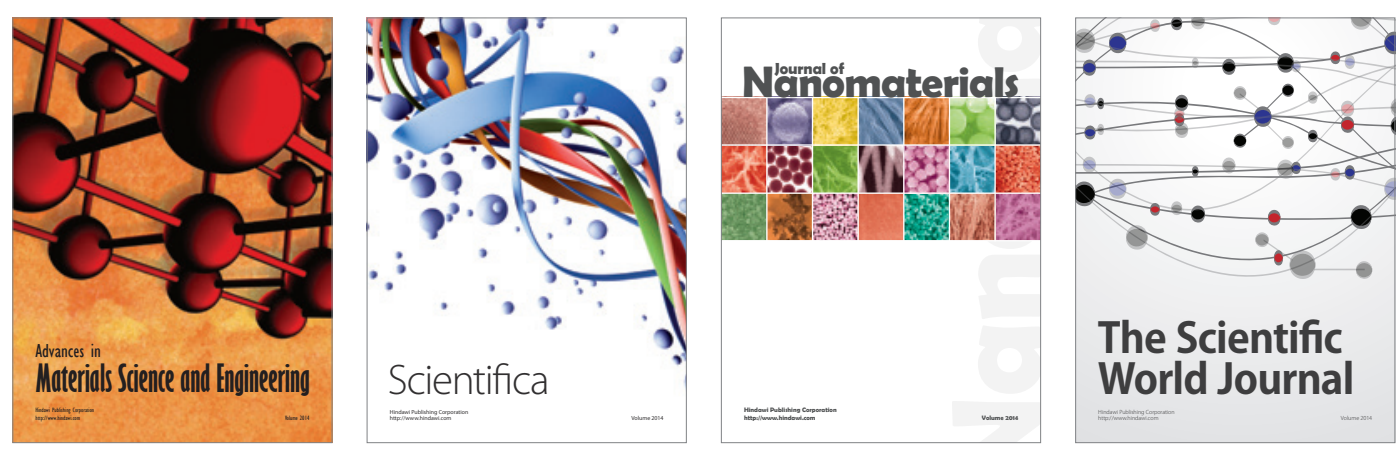

\section{The Scientific World Journal}
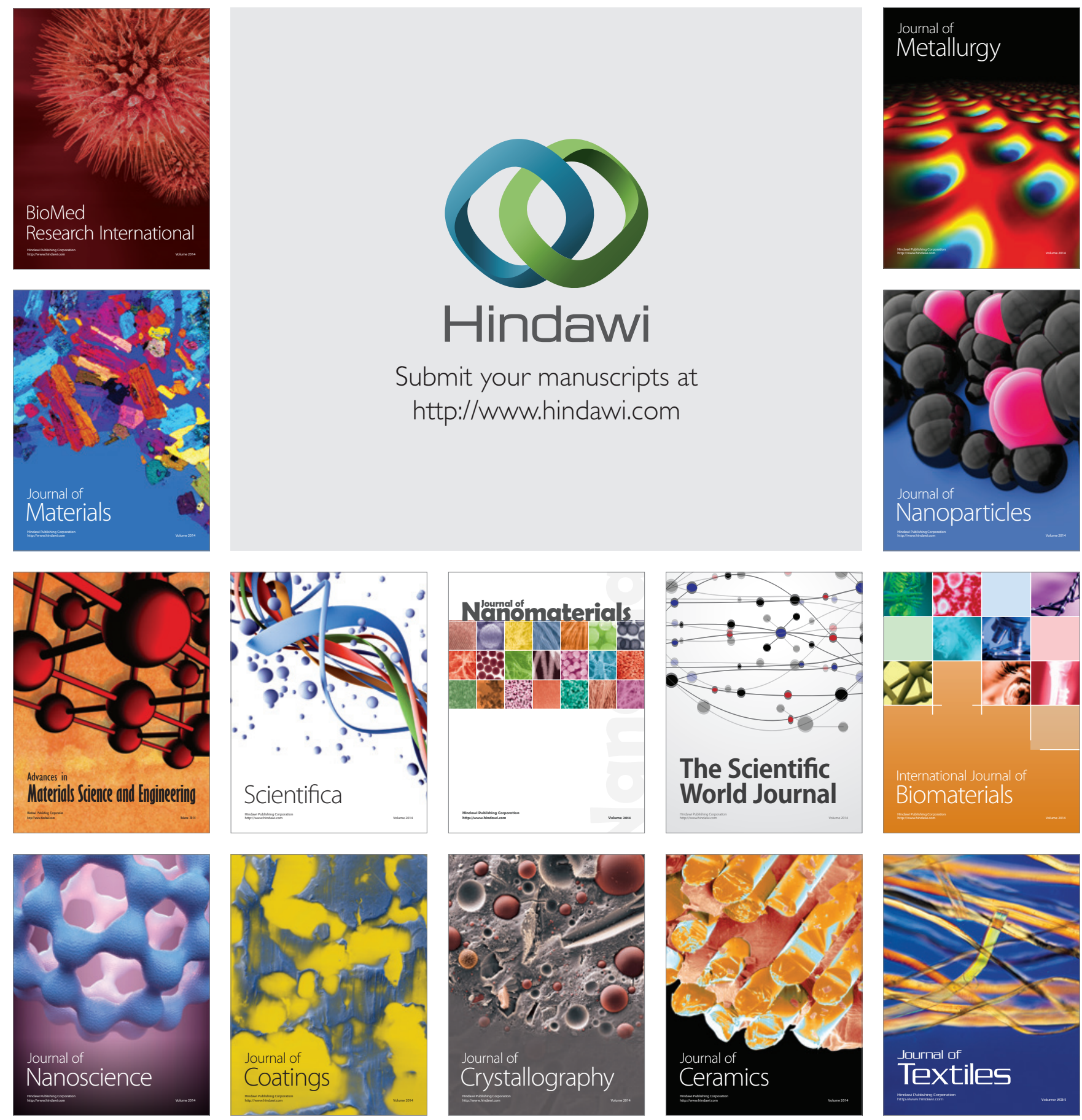